\title{
CDKN2A NM_000077.4:C.247C>T
}

National Cancer Institute

\section{Source}

National Cancer Institute. CDKN2A NM 000077.4:C.247C>T. NCI Thesaurus. Code

C146933.

A nucleotide substitution at position 247 of the coding sequence of the CDKN2A gene where cytosine has been mutated to thymine. 